\title{
Artificial Hepatic Support
}

\author{
Where Are We Now?
}

\author{
Andrew Davenport \\ Royal Free and University College Hospital Medical School, Centre for Nephrology, Royal Free Hospital, \\ London, UK
}

\section{Introduction}

The advent of successful orthotopic liver transplantation for patients with both acute and chronic liver failure has been a major breakthrough in clinical practice, for patients who would have otherwise died [1]. Patients with chronic liver disease are now listed for transplantation well before terminal liver failure, and therefore can potentially wait for a suitable donor liver. However, those with acute hepatic failure [2] can be desperately ill, and may require urgent transplantation. Unfortunately, the number of patients with liver disease awaiting transplantation now exceeds the donation rate. If no liver is immediately available, and the clinical condition of the patient is deteriorating, then the question of artificial liver support arises. Similarly, some patients will have contraindications to transplantation, due to cardiovascular or intracranial instability, sepsis or psychosocial factors [3]. In these cases artificial liver support may help, and so allow subsequent transplantation. Patients with chronic liver disease may develop encephalopathy and hepatorenal syndrome [4] secondary to acute events including sepsis and gastrointestinal hemorrhage. Artificial liver support may help to quicken recovery from such acute events.

Over the years several treatments have been advocated to improve survival in both patients with acute and chronic liver failure. After initial success reported in small selected series, many have not then been substantiated in larger randomized controlled trials.

\begin{tabular}{ll}
\hline KARGER & ( 2001 S. Karger AG, Basel \\
Fax +4161306 1234-5068/01/0191-0001\$17.50/0 \\
$\begin{array}{l}\text { E-Mail karger@karger.ch } \\
\text { www.karger.com }\end{array}$ & $\begin{array}{l}\text { Accessible online at: } \\
\text { www.karger.com/journals/bpu }\end{array}$
\end{tabular}

\section{Dialysis}

The introduction of peritoneal and standard intermittent hemodialysis was shown not to affect the outcome in patients with hepatorenal syndrome [5]. Similarly, more recent series have not shown any significant impact on outcome [6]. Peritoneal dialysis has been advocated in patients with liver failure, however there is both an increased risk of peritonitis [6], coupled with inefficient dialysis due to the changes in peritoneal blood flow. Indeed, when two-liter exchanges are performed, patients may exhibit marked cardiovascular instability [7], thus tidal peritoneal dialysis is preferred.

Conventional dialysis preferentially removes small water-soluble solutes, but not those, which are lipid soluble or bound to albumin. Early reports suggested that hemodialysis using polyacrylonitrile dialysers improved conscious level, and that this was due to the removal of middle-sized solutes [8]. Unfortunately these treatments were often complicated by severe hypotension, and many patients died of cerebral edema.

To improve solute removal during dialysis, Mitzner and colleagues [9] in Rostock developed an albuminbased dialysate, molecular adsorbent recycling system (MARS). This system has been shown to remove bilirubin, bile acids, aromatic amino acids and free fatty acids, by transfer from plasma albumin to dialysate albumin, using a high flux polysulphone dialyzer. Thereafter, the effluent dialysate albumin is regenerated by passage

\footnotetext{
Dr. A. Davenport

Centre for Nephrology, Royal Free Hospital

Pond Street

London NW3 2QG (UK)

E-Mail Andrew.Davenport@rfh.nthames.nhs.uk
} 
through a low flux dialyzer against fresh bicarbonate dialysate and then two charcoal columns. A small randomised prospective controlled trial compared additional MARS treatment to hemodiafiltration in a group of patients with severe chronic liver disease. Although mortality was significantly reduced in the MARS-treated group after 7 and 30 days, by 40 days only 1 patient was still alive [9]. Another group just used fresh albumin-based dialysate and treated 3 patients who had decompensated chronic liver disease [10]. In all 3 cases encephalopathy resolved and two were subsequently successfully transplanted. Both systems reported a mild degree of thrombocytopenia associated with treatment.

\section{Hemofiltration}

Hemofiltration removes a larger spectrum of watersoluble solutes than hemodialysis. Early reports suggested improvement in hepatic encephalopathy and survival in patients with fulminant hepatic failure treated by hemofiltration, and compared to dialysis the nonsurvivors predominantly died of multiorgan failure with severe hepatic necrosis rather than cerebral edema [11]. More recent studies have not borne out the earlier success [12].

Subsequently continuous forms of renal replacement therapy (CRRT) have been developed. Although these resulted in greater cardiovascular and intracranial stability compared to intermittent hemodialysis and/or hemofiltration, they were not shown to significantly improve survival [7]. CRRT did allow stabilisation of the patient, possibly due to thermal losses rather than toxin removal, and allowed the controlled correction of hyponatremia prior to transplantation [7].

\section{Charcoal}

Charcoal hemoperfusion was introduced to try and remove lipid soluble toxins. Several promising studies were published from the early 1980s up to 1992 in patients with acute liver failure, with reports of reduction in grade of encephalopathy and improved survival. However, when the same center then conducted a prospective randomized controlled trial, they showed that charcoal hemoperfusion did not have any additional benefit over conservative management [13].

The BioLogic-DT sorbent system utilises a cellulosic membrane dialyzer and both a charcoal suspension and a sodium-loaded cation exchange resin as a sorbent dialy- sate [14]. In theory, only those solutes which can pass through the cellulosic membrane can be removed. Although there are small studies suggesting an improvement in patients with chronic liver disease who have decompensated [14], others in acute liver failure have failed to show any benefit [15].

\section{Plasma Exchange}

Although high volume plasma exchange and/or plasma immunoadsorption have been reported to improve cardiovascular and intracranial stability in patients with acute liver failure, the results from Copenhagen did not show any significant improvement in patient survival compared to conservative management [16]. Similarly, the results from the Japanese series do not show an obvious improvement with plasma perfusion, apart from a small group with acute viral hepatitis who had $70-80 \%$ survival [17].

\section{Extracorporeal Hepatic Perfusion}

Extracorporeal whole organ perfusion for acute liver failure was first described in 1957. Thereafter, many short uncontrolled series were published using baboon or pig livers, but this technique lost favor due to technical problems. More recently, a case of human extracorporeal perfusion with a human liver that was not suitable for transplantation was used in a young child with acute liver failure [18]. The liver survived for $72 \mathrm{~h}$ during which time the child's intracranial pressure declined, metabolic acidosis corrected, prothrombin time normalised, and coagulation factors V and VII increased. Thus, this treatment may act as a bridge to transplantation.

\section{Hepatocytes}

Two bioartifical livers have been developed, one using primary porcine hepatocytes, the other a transformed human hepatoma cell line (C3A) [19]. To prevent clotting in the porcine system, blood passes through a plasma filter, and the plasma filtrate then perfuses through the porcine bioartifical liver (BAL), and then through a charcoal adsorption column before returning to the patient [20]. Whereas in the extracorporeal liver assist device (ELAD), blood passes directly through two cartridges of human hepatocytes. The initial pilot studies of these devices 
showed that there was some hepatocyte function. However, neither pilot data suggested a major improvement in patient outcome. However, this may have been due to the amount of functioning hepatocyte mass. The initial trials with the ELAD used a single cartridge containing approximately $200 \mathrm{~g}$ of hepatocytes, subsequent trials used $400 \mathrm{~g}$ and the current planned multicenter trial will use $800 \mathrm{~g}$.

One other treatment described as a potential bridge to transplantation is the injection of human hepatocytes, from cadaveric and human donor livers that are unsuitable for solid organ transplantation. Hepatocytes can be injected percutaneously into the spleen or into the splenic vein, and seed into the liver [21].

\section{Summary}

The liver plays a central role in metabolic homeostasis, but also a major role in host-defence mechanisms. There is great debate as to the underlying etiology of what causes the clinical syndrome of acute liver failure, whether it represents toxin accumulation due to defective hepatocyte function, or is due to endothelial and Kupffer cell mediated inflammation secondary to hepatocyte necrosis with resultant endotoxemia, cytokine activation and recruitment of inflammatory cells. Thus, treatments designed to support the patient with liver failure must not only remove toxins, but also provide adequate hepatic function, until sufficient hepatic regeneration occurs, or transplantation.

The history of treating patients with acute hepatic failure is littered with small uncontrolled series advocating one treatment after another. It is important after the debacle of charcoal perfusion that the newer treatments are carefully evaluated by randomized controlled trials. The BioLogic-DT and MARS systems will remove a varying amount of toxins, but do not provide hepatic support. Bioartificial livers, such as the ELAD and hepatocyte infusions, may prove to be the superior treatment, but the question arises as to how many hepatocytes are required.

\section{References}

1 Devlin J, Williams R: Prognosis and consideration of transplantation; in Lee MW, Williams R (eds): Acute Liver Failure. Cambridge, Cambridge University Press, 1997, pp 173-185.

2 O'Grady JG, Williams R: Classification of acute liver failure. Lancet 1993;342:743-748.

3 Williams R, Wendon J: Indications for orthotopic liver transplantation in fulminant hepatic failure. Hepatology 1994;20:S5-S9.

4 Bataller R, Sort P, Gines P, Arroyo V: Hepatorenal syndrome - definition, pathophysiology, clinical features and management. Kid Int 1998;53(suppl 66):S47-S53.

5 Wilkinson SP, Weston MJ, Parsons V, Williams R: Dialysis in the treatment of renal failure in patients with liver disease. Clin Nephrol 1977;8:287-292.

6 Mutimer DJ, Burra P, Neuberger JM, Hubscher S, Buckels JAC, Mayer AD, McMaster P, Elias E: Managing severe alcoholic hepatitis complicated by renal failure. QJ Med 1993;86: 649-656.

7 Davenport A: Is there a role for continuous renal replacement therapies in patients with liver and renal failure? Kid Int 1999;56:(suppl 72): S62-S65.

8 Denis J, Opolon P, Nusinovici V, Granger A, Darnis F: Treatment of encephalopathy during fulminant hepatic failure by hemodialysis with high permeability membrane. Gut 1978;19: 787-793.
9 Stange J, Mitzner SR, Risler T, Erley CM, Lauchart W, Goehl H, Klammt S, Peszynski P, Freytag J, Hickstein H, Löhr M, Liebe S, Schareck W, Hopt UT, Schmidt R: Molecular adsorbent recycling system (MARS): Clinical results of a new membrane based blood purification system for bioartificial liver support. J Artif Organs 1999;23:319-330.

10 Seige M, Kreyman B, Jeschke B, Schweigart U, Kopp K-F, Classen M: Long-term treatment of patients with acute exacerbation of chronic liver failure by albumin dialysis. Transplant Proceeds 1999;31:1371-1375.

11 Opolon P: High permeability membrane hemodialysis and hemofiltration in acute hepatic coma: Experimental and clinical aspects. Int $\mathrm{J}$ Artif Organs 1979:3:354-360.

12 Matsubara S, Okabe K, Ouchi K, Miyazaki Y, Suzuki H, Otsuki M, Matsuno S: Continuous removal of middle molecules by hemofiltration in patients with acute liver failure. Crit Care Med 1990;18:1331-1338.

13 O'Grady JG, Gimson AES, O’Brien CJ, Pucknell A, Hughes RD, Williams R: Controlled trials of charcoal hemoperfusion and prognostic factors in fulminant hepatic failure. Gastroenterology 1988;94:1186-1192.

14 Ash SR, Blake DE, Carr DJ, Carter C, Howard T, Makowka L: Clinical effects of a sorbent suspension dialysis system in treatment of hepatic coma (the BioLogic-DT). Int J Artif Organs 1992;15:151-161.

15 Hughes RD, Pucknell A, Routley D, Langley PG, Wendon JA, Williams R: Evaluation of the BioLogic-DT sorbent-suspension dialyser in patients with fulminant hepatic failure. Int $\mathrm{J}$ Artif Organs 1994;17:657-662.
16 Tygstrup N, Larsen FS, Hansen BA: Treatment of acute liver failure by high volume plasmapheresis; in Lee MW, Williams R (eds): Acute Liver Failure. Cambridge, Cambridge University Press, 1997, pp 267-277.

17 Hida M, Watanabe J, Tanaka K, Kitamura M, Lida T, Hiraga S, Satoli T, Tanaka S, Kawamura Y, Tanaka M: Clinical evaluation of plasmapheresis for hepatic failure. Tokai Exp Clin Med 1992; 17:223-227.

18 McChesney LP, Fagan EA, Rowell DL, Del Reo J, Fabrega F, Millis M, Williams JW: Extracorporeal liver perfusion. Lancet 1999; 353:120-121.

19 Sussman NL, Lake JR: Treatment of hepatic failure - 1996 current concepts and progress towards liver dialysis. Am J Kid Dis 1996;27: 605-621.

20 Rozga J, Podesta L, LePage E, Morsiani E, Moscioni AD, Hoffman MD, Sher L, Villamil F, Woolf G, McGrath M, Kong L, Rosen H, Lanman T, Vierling J, Makowa L, Demetriou AA: A bioartifical liver to treat severe acute liver failure. Ann Surg 1994;218:538-546.

21 Ellis AJ, Sussman NL, Kelly JH, Williams R: Clinical experience with an extracorporeal liver assist device; in Lee MW, Williams R (eds): Acute Liver Failure. Cambridge, Cambridge University Press, 1997, pp 255-265.

22 Habibullah CM, Syed IH, Qamar A, Taher-Uz $Z$ : Human fetal hepatocyte transplantation in patients with fulminant hepatic failure. Transplantation 1994;58:951-952. 